\title{
Development of disability in chronic obstructive pulmonary disease: beyond lung function
}

\author{
Mark D Eisner ${ }^{1,2}$ Carlos Iribarren, ${ }^{3}$ Paul D Blanc, ${ }^{1,2}$ Edward H Yelin, ${ }^{4}$ Lynn Ackerson, ${ }^{3}$ \\ Nancy Byl, ${ }^{5}$ Theodore A Omachi, ${ }^{1}$ Stephen Sidney, ${ }^{3}$ Patricia P Katz ${ }^{4}$
}

${ }^{1}$ Division of Pulmonary and Critical Care Medicine, Department of Medicine, University of California, San Francisco, California, USA

2Division of Occupational and Environmental Medicine, Department of Medicine, University of California, San Francisco, California, USA ${ }^{3}$ Division of Research, Kaiser Permanente, Oakland, California, USA

${ }^{4}$ Institute for Health Policy Studies, Department of Medicine, University of California, San Francisco, California, USA

${ }^{5}$ Department of Physical Therapy and Rehabilitation, University of California, San Francisco, California, USA

\section{Correspondence to}

Mark D Eisner, University of

California, San Francisco, 505

Parnassus Avenue, M1097, San

Francisco, CA 94143-0111.

USA; mark.eisner@ucsf.edu

Received 23 February 2010 Accepted 16 September 2010 Published Online First

3 November 2010

\begin{abstract}
Background COPD is a major cause of disability, but little is known about how disability develops in this condition. Methods The authors analysed data from the Function, Living, Outcomes and Work (FLOW) Study which enrolled 1202 Kaiser Permanente Northern California members with COPD at baseline and re-evaluated 1051 subjects at 2-year follow-up. The authors tested the specific hypothesis that the development of specific nonrespiratory impairments labnormal body composition and muscle strength) and functional limitations (decreased lower extremity function, poor balance, mobility-related dyspnoea, reduced exercise performance and decreased cognitive function) will determine the risk of disability in COPD, after controlling for respiratory impairment (FEV and oxygen saturation). The Valued Life Activities Scale was used to assess disability in terms of a broad range of daily activities. The primary disability outcome measure was defined as an increase in the proportion of activities that cannot be performed of $3.3 \%$ or greater from baseline to 2-year follow-up (the estimated minimal important difference). Multivariable logistic regression was used for analysis.
\end{abstract}

Results Respiratory impairment measures were related to an increased prospective risk of disability (multivariate OR 1.75; $95 \% \mathrm{Cl} 1.26$ to 2.44 for 1 litre decrement of $\mathrm{FEV}_{1}$ and $\mathrm{OR} 1.57$ per $5 \%$ decrement in oxygen saturation; $95 \% \mathrm{Cl} 1.13$ to 2.18). Non-respiratory impairment (body composition and lower extremity muscle strength) and functional limitations (lower extremity function, exercise performance, and mobilityrelated dyspnoea) were all associated with an increased longitudinal risk of disability after controlling for respiratory impairment ( $p<0.05$ in all cases). Nonrespiratory impairment and functional limitations were predictive of prospective disability, above-and-beyond sociodemographic characteristics, smoking status and respiratory impairment (area under the receiver operating characteristic curve increased from 0.65 to 0.75 ; $\mathrm{p}<0.001$ )

Conclusions Development of non-respiratory impairment and functional limitations, which reflect the systemic nature of COPD, appear to be critical determinants of disablement. Prevention and treatment of disability require a comprehensive approach to the COPD patient.

\section{INTRODUCTION}

The recent Institute of Medicine report on comparative effectiveness research identified studies of functional limitations and disability as a priority research area. ${ }^{1}$ The report ranked research on disability as the third most important priority area, with nearly one-fifth of research topics falling within this category. Chronic obstructive pulmonary disease (COPD), because it is one of the top five causes of disability among middle-aged US adults, is a key condition for such disability research. ${ }^{3}$ We have previously shown that adults with COPD have a 10-fold higher risk of disability than members of the general population. ${ }^{4}$ Moreover, COPD is associated with greater disability than other chronic health conditions, such as diabetes or heart disease. ${ }^{4}$ COPD is also associated with reduced ability to perform basic self-care tasks necessary for survival and activities necessary for living independently. ${ }^{5-10}$ Although prior research indicates that COPD-related disability is a substantive problem, very little is known about how the disease progresses to disability.

To study the progression to COPD-related disability, we have adapted a specific conceptual disablement model proposed by Verbrugge and Jette. ${ }^{11}$ In this model, the central pathway begins with the impact of disease pathology, which includes specific biochemical or physiological alterations, on impairments. Impairments are specific structural or functional alterations of organ systems, such as reduced pulmonary function, that lead to functional limitation, which are decrements of basic physical or mental actions (eg, mobility, strength, and central cognitive and emotional functions). Functional limitation in turn leads to disability, which is difficulty in performing activities or roles that are normal for one's age and sex. These range from activities of daily living, which are necessary for survival, to discretionary activities that make life meaningful, such as socialising and recreation.

Based on this disablement model, we tested a specific theory of how disability develops in COPD. We reasoned that respiratory impairment alone was unlikely to explain most of the disability risk. We hypothesised that, for a given level of respiratory impairment, the development of specific non-respiratory impairments (abnormal body composition and muscle strength) and functional limitations (decreased lower extremity function, poor balance, mobility-related dyspnoea, reduced exercise performance and decreased cognitive function) will determine the risk of disability in COPD.

\section{METHODS}

\section{Recruitment and follow-up of the cohort}

The Function, Living, Outcomes and Work (FLOW) study of COPD is an ongoing prospective cohort study of adult members of an integrated healthcare 
delivery system with a physician's diagnosis of COPD. Recruitment methods have been previously reported in detail. $^{12-15}$ We recruited a population-based cohort of 1202 Kaiser Permanente Medical Care Program (KPMCP) members who were recently treated for COPD using a validated algorithm based both on healthcare utilisation and pharmacy dispensing for COPD. ${ }^{16} \mathrm{~A}$ diagnosis of COPD was confirmed, based on interviews and spirometry, using Global Initiative for Chronic Obstructive Lung Disease (GOLD) criteria. At baseline assessment, we conducted structured telephone interviews that ascertained sociodemographic characteristics, COPD clinical history, health status and disability. ${ }^{12-14}$ Research clinic visits included spirometry and other physical assessments.

Approximately 2 years later, we conducted follow-up telephone interviews that ascertained COPD status and disability. Of the 1202 subjects interviewed at baseline, 40 subjects subsequently died before follow-up interview. We completed interview follow-up in 1051 subjects, which reflects an $87 \%$ completion rate $(90 \%$ among subjects who were still alive). The study was approved both by the University of California, San Francisco Committee on Human Research and the Kaiser Foundation Research Institute's institutional review board and all participants provided written informed consent.

\section{Baseline characteristics}

Personal characteristics were assessed by structured telephone interview. These included sociodemographic characteristics such as age, sex, educational attainment and income, which were measured as previously described. ${ }^{12-15}$ Cigarette smoking was assessed using questions developed for the National Health Interview Survey. ${ }^{17}$

\section{Respiratory impairment}

To assess respiratory impairment, we conducted spirometry according to American Thoracic Society (ATS) Guidelines. ${ }^{18} 19$ We used the EasyOne Frontline spirometer (ndd Medical Technologies, Chelmsford, Massachusetts, USA), which is known for its reliability, accuracy and durability. ${ }^{20} 21$ The Easyone spirometer has been used by large scale multicenter international epidemiologic studies of COPD. ${ }^{21} 22$ Baseline oxygen saturation was measured at rest in the seated position using the Nellcor N-180 (Covidien-Nellcor, Boulder, Colorado, USA).

\section{Non-respiratory impairment assessment: body composition and muscle strength}

We assessed bioelectrical impedance as a measure of body composition using the Quantum II Bioelectrical Body Composition Analyser (RJL Systems, Clinton Township, Michigan, USA). To calculate lean and fat mass, we used established sex-specific regression equations. ${ }^{23}$ Based on our previous work, we chose the lean-to-fat ratio as a key measure of body composition. ${ }^{24}$

The ratio was calculated by dividing lean mass by fat mass. The lean-to-fat ratio is advantageous because it is independent of body size and avoids the collinearity between lean and fat mass. Moreover, the ratio is more closely related to functional limitation than lean mass or fat mass alone. ${ }^{23} 25$

Isometric skeletal muscle strength was evaluated following standard manual muscle testing procedures. ${ }^{26} \mathrm{~A}$ hand-held dynamometer was used to improve the objectivity of the force estimates (MicroFet2 dynamometer; Saemmons Preston, Bolingbrook, Illinois, USA). ${ }^{26}$ The examiners were trained in manual muscle testing by the same experienced physical therapist. Each of the examiners practiced testing control subjects until there was agreement between the raters $90 \%$ of the time within five pounds of force.

Knee extensor (quadriceps), hip extensor and hip abductor (ie, gluteus medius) strength were measured because these muscles are considered critical for standing and walking. In addition, previous work has also suggested the importance of quadriceps weakness as a predictor of reduced maximal exercise performance in COPD. ${ }^{27-30}$ In the upper extremity, power grip, precision grip and elbow flexion strength were measured because these muscles are important for performing many daily activities. We have previously described these methods in detail. ${ }^{13}$

\section{Assessment of functional limitations}

The central distinction between functional limitation and disability can be illustrated by the difference between 'action' and 'activity'. 11 Specifically, functional limitation indicates decreased capacity or capability, whereas disability refers to activity in a social or role-based context. For example, measurement of distance walked in 6 min (Six Minute Walk Test) reflects functional limitation; difficulty walking to perform errands comprises disability.

We assessed functional limitations, which are decrements in basic physical or mental actions, using a multifaceted physical assessment. Lower extremity function was measured using the validated Short Physical Performance Battery (SPPB) which includes tests of standing balance, gait speed and chair stand. ${ }^{31-33}$ A summary performance score integrates the three performance measures, ranging from 0 to 12 . Previous work indicates that the battery has excellent inter-observer reliability, test-retest reliability and predictive validity. ${ }^{31-33}$

We also measured balance with the functional reach test. This test measures how far a subject can reach forward beyond arm's length while maintaining a fixed base of support in the standing position, without losing balance. ${ }^{34}$ The functional reach test has excellent test-retest reliability and validity. ${ }^{34-37}$

Submaximal exercise performance was measured using the Six Minute Walk Test, which has been widely used in studies of COPD. ${ }^{38} 39$ We measured submaximal rather than maximal exercise performance because most daily activities are likely to require sustained submaximal exertion, rather than maximal exercise levels. We used a standardised flat, straight course of $30 \mathrm{~m}$ in accordance with American Thoracic Society (ATS) Guidelines. ${ }^{40}$

Mobility-related dyspnoea, which is the extent of mobility limitation due to breathlessness, was measured by the British Medical Research Council (MRC) dyspnoea scale. ${ }^{41}$ Used for many years, this scale has five items that assess the degree of dyspnoea during basic mobility tasks, ranging from dyspnoea with strenuous exercise (grade 1) to inability to leave the house due to dyspnoea (grade 5). The MRC dyspnoea scale has been used extensively; its construct validity is supported by correlation with health-related quality of life, exercise performance and ability to perform activities of daily living. ${ }^{42-44}$

Cognitive function was measured using the Mini-Mental State Examination, which is the leading screening test for cognitive impairment in North America. ${ }^{45}$ The 11-item instrument assesses orientation, recall ability, short-term memory and arithmetic ability. ${ }^{46}$ It evaluates most of the main domains of cognitive status and has been extensively validated. ${ }^{45-50} \mathrm{We}$ used the recommended cut-point score of $<24$ points to indicate cognitive impairment. ${ }^{51}$

\section{Study outcome: measurement of COPD-related disability}

We conceptualise disability as the impact of COPD on a broad range of daily activities. These activities include those that are 
necessary for survival, but also social, spiritual, and recreational activities. To measure disability, as this comprehensive construct, we used the Valued Life Activities scale which was originally developed for arthritis and subsequently adapted for use in asthma and COPD. ${ }^{52-55}$ The scale measures difficulty with functioning in 22 distinct activity domains, ranging from self-care to social and recreational pursuits. For each activity domain, subjects rate the amount of difficulty that they have because of their breathing problems on a scale from 0 to $10(0=$ no difficulty, $10=$ unable to perform the activity). Based on subject responses, the proportion of activities that they cannot perform is calculated as the principle measure of COPDrelated disability. The proportion has a theoretical range from 0 to 1.0 (or 0 to $100 \%$ in percentage terms).

The disability scale was administered at baseline and follow-up telephone interviews and change scores were calculated. We used the method of Wywrich et al to estimate the 'minimal important difference' in score, based on the SE of measurement (SEM). ${ }^{56} 57$ The SEM is calculated as the SD of a score multiplied by the square root of 1 minus the reliability coefficient. ${ }^{56}$ Using this method, we estimated that the minimal important difference is an absolute increase in the proportion of activities that cannot be performed of $3.3 \%$ from baseline to 2 -year follow-up assessments. Based on the continuous disability score, we defined the primary measure of prospective disability - a dichotomous study outcome-as a score increase of at least 3.3\% from baseline. We also defined a secondary disability outcome as the development of any new activity domain that cannot be performed due to COPD among subjects who had reported no baseline disability.

\section{Statistical analysis}

Statistical analysis was conducted using SAS software, version 9.1 (SAS Institute, Inc.) and STATA 10. Bivariate analysis was conducted with the t-test for continuous variables and $\chi^{2}$ test for dichotomous variables. A 2 -tailed $p$ value of $<0.05$ was used to indicate statistical significance.

Multivariable logistic regression analysis was used to evaluate the impact of respiratory impairment $\left(\mathrm{FEV}_{1}\right.$ and oxygen saturation) on the prospective risk of disability after controlling for potential confounding variables. Confounders were selected a priori based on our prior work examining the sociodemographic and personal factors that are related to physical activity and disability: age, sex, race, height, educational attainment, household income and smoking status. ${ }^{4} 59$ The analysis was repeated for the primary disability outcome (a longitudinal increase of $3.3 \%$ or more in the percentage of activities that cannot be performed) and the secondary disability outcome (development of one or more new activity domains that cannot be performed, among subjects with no baseline disability).

We used multivariable logistic regression analysis to examine the impact of each non-respiratory impairment and functional limitation on the prospective risk of disability from baseline to 2-year follow-up assessment. Because the non-respiratory impairment and functional limitation tests (eg, Short Physical Performance Battery) yield continuous variables, we defined non-respiratory impairment/functional limitation as the lowest quartile of performance on an a priori basis. The exception is cognitive impairment, which has a well-established cut-point $\left(<24\right.$ points) on the Mini-Mental State Examination. ${ }^{51}$

To examine the impact of non-respiratory impairment/functional limitations on the prospective risk of disability, we compared three nested logistic regression models. Model 1 included baseline sociodemographic and personal characteristics (age, sex, race, educational attainment, household income and
Table 1 Baseline characteristics among adults with COPD by follow-up status

\begin{tabular}{|c|c|c|c|}
\hline & Cohort $(n=1051)$ & No follow-up $(n=151)$ & p-Value \\
\hline Age (mean years, SD) & $58.3(6.2)$ & $57.6(6.4)$ & 0.19 \\
\hline Female sex (n, \%) & $620(59 \%)$ & 71 (47\%) & 0.006 \\
\hline Race (white, non-hispanic) & $725(69 \%)$ & $87(58 \%)$ & 0.006 \\
\hline \multicolumn{4}{|l|}{ Educational attainment $(\mathrm{n}, \%)$} \\
\hline High school or less & $300(29 \%)$ & $51(34 \%)$ & 0.03 \\
\hline Some college & $453(43 \%)$ & $72(48 \%)$ & \\
\hline College degree+ & $298(28 \%)$ & $28(19 \%)$ & \\
\hline \multicolumn{4}{|l|}{ Household income $(n, \%)^{*}$} \\
\hline Low income (<\$20K) & $103(9.8 \%)$ & $26(17 \%)$ & 0.064 \\
\hline Medium income ( $\$ 20-80 \mathrm{~K})$ & $614(58 \%)$ & $85(56 \%)$ & \\
\hline High income (>\$80K) & $247(24 \%)$ & $29(19 \%)$ & \\
\hline \multicolumn{4}{|l|}{ Smoking history (n, \%) } \\
\hline Past smoker & $571(54 \%)$ & $73(48 \%)$ & 0.032 \\
\hline Current smoker & $330(31 \%)$ & $63(42 \%)$ & \\
\hline Never smoker & $150(14 \%)$ & $15(10 \%)$ & \\
\hline Forced expiratory volume in $1 \mathrm{~s}$ & $1.80(0.77)$ & $1.77(0.81)$ & 0.67 \\
\hline
\end{tabular}

Proportions are column \%.

Forced expiratory volume in $1 \mathrm{~s}$ per cent was $63 \%$ in both groups. The proportion of subjects who were GOLD Stage II or higher was similar in both groups $(61 \%)$.

${ }^{*} \mathrm{~A}$ minority of all subjects $(8 \%)$ declined to report their income.

smoking history). Model 2 included the same variables plus respiratory impairment measures ( $\mathrm{FEV}_{1}$ and oxygen saturation). Model 3 included all previous variables plus non-respiratory impairment (body composition and skeletal muscle strength) and functional limitations (lower extremity function, balance, submaximal exercise performance, dyspnoea on exertion, and cognitive impairment). The c-statistic was used to quantify the area under the receiver operating characteristic (ROC) curve, which represents the predictive or discriminatory capacity of each model. The method of Delong and colleagues was used to statistically compare the area under each ROC curve. ${ }^{60}$ The incremental contribution of respiratory impairment to the longitudinal prediction of disability was determined by comparing model 2 to model 1 ; the incremental impact of nonrespiratory impairment/functional limitation was derived from comparing model 3 to model 2 .

To evaluate a more severe spectrum of COPD, we repeated the ROC analysis re-defining COPD as an $\mathrm{FEV}_{1} / \mathrm{FVC}$ ratio $<0.70$ and $\mathrm{FEV}_{1}<80 \%$ predicted (ie, GOLD stage II or greater; consistent with the Burden of Lung Disease (BOLD) Study strategy). ${ }^{22}$ This sensitivity analysis focused on subjects with more severe disease.

\section{RESULTS}

\section{Baseline characteristics}

Completion of the 2-year follow-up assessment was high (87\%). As shown in table 1, the cohort completing follow-up was somewhat more likely to be female, white non-hispanic, better educated, higher income and past (as opposed to current) smoker. There were no differences in age or lung function $\left(\mathrm{FEV}_{1}\right)$ by follow-up status.

\section{Respiratory impairment and the prospective risk of disability} At baseline, $26 \%$ of subjects indicated disability (one or more activity domains that they were unable to perform). The proportion of activities that they could not perform ranged from $0 \%$ to $68 \%$. In the entire cohort, 110 subjects with COPD developed the primary disability outcome measure (10.5\%; $95 \%$ CI 8.7 to $12.5 \%$ ). Among subjects without baseline disability, a slightly lower proportion developed the secondary disability outcome ( $\mathrm{n}=66$; $8.5 \%$; $95 \%$ CI 6.6 to $10.7 \%$ ). 
Table 2 Respiratory impairment and prospective risk of disability in COPD

\begin{tabular}{|c|c|c|}
\hline \multirow[b]{2}{*}{$\begin{array}{l}\text { Respiratory impairment } \\
\text { measure }\end{array}$} & \multicolumn{2}{|c|}{ Prospective disability measure* } \\
\hline & $\begin{array}{l}\text { Increase in proportion } \\
\text { of activities unable to } \\
\text { perform }(n=1051)\end{array}$ & $\begin{array}{l}\text { Secondary } \\
\text { Development of } \geq 1 \text { activity } \\
\text { unable to perform in those } \\
\text { with no baseline disability } \\
(n=777)\end{array}$ \\
\hline \multicolumn{3}{|l|}{ Forced expiratory volume in $1 \mathrm{~s}$} \\
\hline Base model $†$ & $\begin{array}{l}1.95(1.41 \text { to } 2.70) \\
\mathrm{p}<0.0001\end{array}$ & $\begin{array}{l}1.95(1.28 \text { to } 2.98) \\
p=0.002\end{array}$ \\
\hline Base model + covariates $\dagger$ & $\begin{array}{l}1.75(1.26 \text { to } 2.44) \\
p=0.0009\end{array}$ & $\begin{array}{l}1.81(1.17 \text { to } 2.80) \\
p=0.007\end{array}$ \\
\hline \multicolumn{3}{|l|}{ Baseline oxygen saturation } \\
\hline Base model & $\begin{array}{l}1.70(1.23 \text { to } 2.34) \\
p=0.0012\end{array}$ & $\begin{array}{l}1.45(1.00 \text { to } 2.12) \\
p=0.053\end{array}$ \\
\hline Base model + covariates & $\begin{array}{l}1.57(1.13 \text { to } 2.18) \\
p=0.008\end{array}$ & $\begin{array}{l}1.33(0.90 \text { to } 2.0) \\
p=0.16\end{array}$ \\
\hline \multicolumn{3}{|c|}{$\begin{array}{l}\text { *Incident disability was based on two measures. Primary disability outcome }=\text { an increase } \\
\text { in the proportion of activities that subject is unable to perform from wave } 1 \text { to wave } 2 \text {. A } \\
\text { significant increase was defined as that exceeding } 1 \mathrm{SE} \text { of measurement (see Methods). } \\
\text { Secondary outcome was development of at least one new activity that subject is unable to } \\
\text { perform among subcohort who had no disability at baseline. } \\
\text { †Results are from logistic regression analysis and are presented as } 0 \mathrm{Rs}(95 \% \mathrm{Cls}) \text {. ORs are } \\
\text { expressed for a } 1 \text { I decrement of FEV } \mathrm{F}_{1} \text { and } 5 \% \text { decrement of oxygen saturation. Baseline } \\
\text { model used the following predictor variables: respiratory impairment measure plus age, sex, } \\
\text { race, and height. Covariates (potential confounders) = race, educational attainment, } \\
\text { household income, and smoking status. }\end{array}$} \\
\hline
\end{tabular}

Respiratory impairment measures were related to the development of COPD-related disability. Greater lung function impairment, as evidenced by lower $\mathrm{FEV}_{1}$, was associated with a greater longitudinal risk of the primary disability outcome after controlling for covariates (OR 1.75 per 11 decrement; $95 \%$ CI 1.26 to 2.44 ) (table 2). Lower oxygen saturation was also related to a greater risk of developing disability (OR 1.57 per $5 \%$ decrement; $95 \%$ CI 1.13 to 2.18). Analysis of the secondary disability outcome revealed similar effect estimates for $\mathrm{FEV}_{1}$; the estimates were slightly lower for oxygen saturation (table 2).

\section{Non-respiratory impairment/functional limitations and the prospective risk of disability}

Both non-respiratory impairment domains were individually associated with a greater prospective risk of disability after controlling for respiratory impairment and other covariates (table 3). Decreased lower extremity muscle strength, as evidenced by strength of the quadriceps, hip flexors and hip abductors, was associated with a higher risk of developing disability (OR 1.93; 95\% CI 1.22 to 3.05 , OR 1.64; 95\% CI 1.03 to 2.59 , and OR 1.80 ; $95 \%$ CI 1.15 to 2.84 , respectively). Abnormal body composition, as measured by low lean-to-fat ratio, was also related to a greater risk of COPD-related disability (OR 1.80; 95\% CI 1.08 to 3.02). Analysis of the secondary disability outcome measure revealed similar results for muscle strength (albeit with wider CIs from the smaller sample size in this analysis); body composition was not statistically related to the secondary disability outcome.

Many of the functional limitation domains were associated with a higher longitudinal risk of disability, after controlling for respiratory impairment. Poor lower extremity functioning (OR 2.57; 95\% CI 1.65 to 4.01) and exercise performance (OR 2.93; $95 \%$ CI 1.90 to 4.53 ) were related to a greater risk of COPD-related disability. Mobility-related dyspnoea was also related to greater disability risk (OR 2.93; 95\% CI 1.80 to 4.75). Analysis of the secondary disability outcome revealed similar results, except that poorer balance was additionally associated with a higher risk of disability (OR 2.22; 95\% CI 1.27 to 3.88$)$.
Non-respiratory impairment/functional limitations increased the prospective risk of disability after taking respiratory impairment and other personal characteristics into account. Addition of respiratory impairment measures $\left(\mathrm{FEV}_{1}\right.$ and oxygen saturation) to the base logistic regression model including baseline sociodemographic and personal characteristics increased the area under the ROC curve from 0.65 to $0.69(p=0.029)$ (table 4, figure 1A). When non-respiratory impairment/functional limitations were added to the model, the area under the ROC curve increased further to $0.75(p=0.003)$. The results were highly similar for a sensitivity analysis of the cohort with more severe COPD (GOLD Stage II or higher) (table 4, figure 1B). The results were also highly similar for the secondary disability outcome (results were $0.67,0.70$ and 0.78 , respectively).

\section{DISCUSSION}

Prospective development of disability was a common occurrence in our cohort of younger adults with COPD during the 2-year follow-up period (approximately 1 in 10 subjects). Although respiratory impairment increased the longitudinal risk of disability, the development of non-respiratory impairment and functional limitations in body systems remote from the lung had a greater impact on disablement. Muscle strength, lower

Table 3 Non-respiratory impairment/functional limitations and the prospective risk of COPD-related disability

\begin{tabular}{|c|c|c|}
\hline \multirow[b]{2}{*}{ Predictor variable* } & \multicolumn{2}{|c|}{ Prospective disability measure } \\
\hline & $\begin{array}{l}\text { Primary outcome } \dagger \\
\text { Increase in proportion } \\
\text { of activities unable to } \\
\text { perform }(n=1051)\end{array}$ & $\begin{array}{l}\text { Secondary outcome } \\
\text { Development of } \geq 1 \\
\text { unable to perform in } \\
\text { with no baseline dis } \\
(n=777)\end{array}$ \\
\hline \multicolumn{3}{|c|}{ Non-respiratory impairment* } \\
\hline Body composition & $\begin{array}{l}1.80(1.08 \text { to } 3.02) \\
p=0.025\end{array}$ & $\begin{array}{l}1.42(0.71 \text { to } 2.82) \\
p=0.32\end{array}$ \\
\hline \multicolumn{3}{|l|}{ Muscle strength } \\
\hline Quadriceps & $\begin{array}{l}1.93(1.22 \text { to } 3.05) \\
p=0.0052\end{array}$ & $\begin{array}{l}1.83(0.98 \text { to } 3.40) \\
p=0.057\end{array}$ \\
\hline Hip flexors & $\begin{array}{l}1.64(1.03 \text { to } 2.59) \\
p=0.036\end{array}$ & $\begin{array}{l}1.83(0.98 \text { to } 3.33) \\
p=0.052\end{array}$ \\
\hline Hip abductors & $\begin{array}{l}1.80(1.15 \text { to } 2.84) \\
p=0.011\end{array}$ & $\begin{array}{l}2.22(1.21 \text { to } 4.05) \\
p=0.01\end{array}$ \\
\hline Elbow flexors & $\begin{array}{l}1.51(0.93 \text { to } 2.45) \\
p=0.093\end{array}$ & $\begin{array}{l}1.69(0.89 \text { to } 3.20) \\
P=0.11\end{array}$ \\
\hline Grip & $\begin{array}{l}0.86(0.51 \text { to } 1.47) \\
p=0.59\end{array}$ & $\begin{array}{l}0.57(0.26 \text { to } 1.28) \\
p=0.18\end{array}$ \\
\hline Pinch & $\begin{array}{l}0.67(0.39 \text { to } 1.15) \\
p=0.15\end{array}$ & $\begin{array}{l}0.64(0.31 \text { to } 1.30) \\
p=0.22\end{array}$ \\
\hline
\end{tabular}

Functional limitations*

Lower extremity functioning 2.57 (1.65 to 4.01$) \quad 3.20$ (1.76 to 5.81$)$

Balance

$\mathrm{p}<0.0001$

$1.41(0.90$ to 2.21$) \quad 2.18(1.23$ to 3.86$)$

$\mathrm{p}=0.14$

$\mathrm{p}<0.0001$

$2.18(1.23$ to 3.86$)$

$2.93(1.90$ to 4.53$)$

$4.01(2.23$ to 7.20$)$

$\mathrm{p}<0.0001$

Mobility-related dyspnoea $\quad 2.93(1.80$ to 4.75$)$

$\mathrm{p}<0.0001$

$\mathrm{p}<0.0001$

$4.55(2.22$ to 9.30$)$

$\mathrm{p}<0.0001$

Cognitive dysfunction

$1.34(0.62$ to 2.90$)$

$1.53(0.51$ to 4.57$)$

$\mathrm{p}=0.44$

*For each non-respiratory impairment/functional limitation, poor function was defined as the lowest quartile of the distribution (except cognitive impairment which used a standard cutpoint of 24 points on the Mini-Mental Status Examination). Measurements = body composition (lean/fat ratio from bioelectrical impedance), muscle strength testing (dynamometry), lower extremity functioning (Short Physical Performance Battery), balance (Functional Reach Test), exercise performance (Six Minute Walk Test), and dyspnoea (Modified MRC Dyspnoea Scale).

†Individual multivariable logistic regression analyses controlling for age, sex, race, height, educational attainment, household income, smoking status, and respiratory impairment ( $\mathrm{FEV}_{1}$ and oxygen saturation). All results are ORs ( $95 \% \mathrm{Cls}$ ) with accompanying $p$ values. 
Table 4 Relative contribution of respiratory impairment and non-respiratory impairment/functional limitations to prospective risk of COPD-related disability

\begin{tabular}{|c|c|c|}
\hline \multirow[b]{2}{*}{ COPD severity measure } & \multicolumn{2}{|c|}{$\begin{array}{l}\text { Area under the receiver operating characteristic } \\
\text { curve }(95 \% \mathrm{Cl})\end{array}$} \\
\hline & Entire cohort $(n=1051)$ & GOLD Stage II or greater \\
\hline $\begin{array}{l}\text { Model 1: sociodemographic and personal } \\
\text { characteristics }\end{array}$ & $0.65(0.59$ to 0.70$)$ & $0.66(0.60$ to 0.72$)$ \\
\hline $\begin{array}{l}\text { Model 2: sociodemographic } \\
\text { characteristics + respiratory impairment }\end{array}$ & $0.69(0.63$ to 0.74$)$ & $0.70(0.65$ to 0.76$)$ \\
\hline $\begin{array}{l}\text { Model 3: sociodemographic } \\
\text { characteristics + respiratory impairment } \\
+ \text { non-respiratory impairment/functional } \\
\text { limitations }\end{array}$ & $0.75(0.70$ to 0.80$)$ & $0.78(0.72$ to 0.84$)$ \\
\hline Overall comparison & $\mathrm{p}<0.001$ & $\mathrm{p}<0.001$ \\
\hline Comparison of model 2 vs model 1 & $p=0.029$ & $\mathrm{p}=0.064$ \\
\hline Comparison of model 3 vs model 2 & $\mathrm{p}=0.003$ & $p=0.0017$ \\
\hline
\end{tabular}

extremity function, exercise performance and mobility-related dyspnoea were potent risk factors for disability, even after taking lung function impairment into account. These results require a paradigm shift in COPD: the assessment and treatment of airway obstruction, which have been the cornerstones of treatment, will not be sufficient to prevent the development of COPD-related disability.

Although cross-sectional studies have found a high prevalence of activity restriction in COPD, longitudinal estimates of disablement are rare. ${ }^{4-10}$ The SUPPORT study reported that more than half of adults hospitalised for COPD exacerbation subsequently had diminished ability to perform activities of daily living. ${ }^{10}$ In addition, most studies of COPD-related disability have focused on a restricted range of daily activities, such as activities of daily living which are necessary for survival. ${ }^{4-10}$ Other studies are limited by small sample size and focus on severe COPD. ${ }^{4-10}$ Consequently, our adds important new information by prospectively elucidating the development of disability using a broad measure of daily activities in a cohort with a wide range of disease severity.

Our study advances the field because it systematically evaluated the impact of extra-pulmonary impairment and functional limitations on the prospective risk of disability in COPD, after accounting for respiratory impairment. Other studies have individually found that lung function, muscle strength or exercise capacity are related to performance of daily activities. ${ }^{30} 61-66$ But none of these studies evaluated disability of a broad range of daily activities, comprehensively evaluated a functional limitations and ascertained prospective disability endpoints. Consequently, our work builds on these previous studies and establishes that non-respiratory impairment and physical functional limitations are the main drivers of the disablement process in COPD.

Our study has several limitations. There is some possibility of misclassification of COPD, although we performed rigorous steps to avoid it. The inclusion criteria required a physician diagnosis of COPD, healthcare utilisation for COPD, and dispending of COPD medications, which was designed to increase the accuracy of case ascertainment. We also previously demonstrated the validity of our approach using medical record review. ${ }^{16}$ Nonetheless, we acknowledge this potential limitation.

Although we had excellent cohort retention (90\% of living subjects were re-interviewed), it is possible that selection bias could have been introduced by losses to follow-up by death or other factors. For example, there were some differences in sociodemographic characteristics by follow-up status. There were no differences in age or lung function, but the retained cohort had
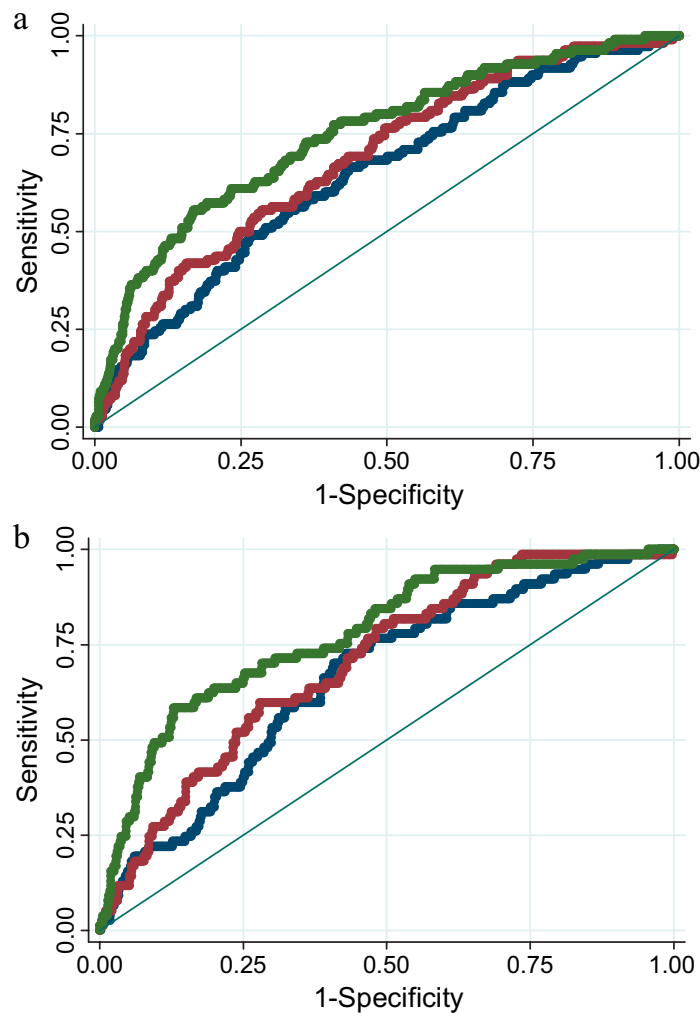

Figure 1 Non-respiratory impairment/functional limitations increase the risk of incident disability in COPD. Receiver operating characteristic curves for the prospective risk of incident disability defined as an increase in the proportion of activities that the subject is unable to perform. Blue curve is for sociodemographic characteristics and smoking status (age, sex, race, height, educational attainment, household income, smoking status). Red line also includes respiratory impairment ( $\mathrm{FEV}_{1}$ and oxygen saturation). Green line includes all previous variables plus non-respiratory impairment (muscle strength, body composition) and functional limitations (lower extremity function, balance, exercise performance, mobility-related dyspnoea, and cognitive impairment). Each curve was statistically different from the others $(p<0.001)$. Figure $1 \mathrm{~A}$ depicts the entire cohort. Figure 1B depicts the cohort with COPD GOLD Stage II or greater (more severe COPD). 
somewhat higher socioeconomic status. Because lower social class is associated with a greater risk of poor health status and disability, our results likely underestimate the development of COPD-related disability. To the extent that functional limitations are greater in the group without follow-up, the analysis would also underestimate the impact of functional limitations on the risk of disability. Consequently, any bias introduced would be conservative.

Because our goal is ultimately disability prevention, we intentionally recruited younger subjects with COPD (aged 45-65 years). As a result, this age range may limit conclusions about elderly persons with COPD. Moreover, our patients were all insured with access to healthcare services. Our results may not fully apply to persons who are not receiving treatment for COPD. The demographic and socioeconomic characteristics of Northern California Kaiser Permanente members, however, are similar to those of the regional population. ${ }^{67}$ There is also no evidence of systematic inclusion or exclusion of healthy persons into the KP system. ${ }^{68}$ Overall, KPMCP members are likely similar to the general US population.

By elucidating the pathway to COPD-related disability, our goal is to provide a scientific basis for the screening and prevention of COPD-related disability. Although measurement of lung function, which is a cornerstone of clinical practice guidelines, predicts disability, it does not by itself fully characterise disability risk. Development of non-respiratory impairment and functional limitations, which reflect the systemic nature of COPD, are critical determinants of disablement. Consequently, medical management may need to be complemented by comprehensive rehabilitative strategies aimed at the diverse extra-pulmonary manifestations of COPD to prevent disability and restore of function.

Funding National Heart, Lung, and Blood Institute/National Institutes of Health R01HL077618 and K24 HL 097245; Flight Attendant Medical Research Institute (FAMRI Bland Lane Center of Excellence on Secondhand Smoke). This publication was also supported by NIH/NCRR UCSF-CTSI Grant Number UL1 RR024131. Its contents are solely the responsibility of the authors and do not necessarily represent the official views of the NIH.

Competing interests MDE completed this study while he was a full time member of the University of California San Francisco. Currently, he is a full time employee of Genentech, Inc. and continues to have a faculty position at University of California San Francisco. He has no financial interest in the topic of this manuscript. No other authors have declared a competing interest.

Ethics approval This study was conducted with the approval of the UCSF, KPNC.

Provenance and peer review Not commissioned; externally peer reviewed.

\section{REFERENCES}

1. Iglehart JK. Prioritizing comparative-effectiveness research - IOM recommendations. N Engl J Med 2009;361:325-8.

2. Mannino DM, Homa DM, Akinbami LJ, et al. Chronic obstructive pulmonary disease surveillance - United States, 1971-2000. MMWR Surveill Summ 2002;51:1-16.

3. Verbrugge LM, Patrick DL. Seven chronic conditions: their impact on US adults' activity levels and use of medical services. Am J Public Health 1995;85:173-82.

4. Eisner MD, Yelin EH, Trupin L, et al. The Influence of Chronic Respiratory Conditions on Health Status and Work Disability. Am J Public Health 2002;92:1506-13.

5. Peach H, Pathy MS. Follow-up study of disability among elderly patients discharged from hospital with exacerbations of chronic bronchitis. Thorax 1981;36:585-9.

6. Isoaho R, Puolijoki $\mathrm{H}$, Huhti $\mathrm{E}$, et al. Chronic obstructive pulmonary disease and selfmaintaining functions in the elderly-a population-based study. Scand J Prim Health Care 1995;13:122-7.

7. Kiviloog J, Irnell L, Eklund G. Course and severity of bronchial asthma and chronic bronchitis in a local Swedish population sample. Scand J Respir Dis 1975:56:129-37.

8. Graydon JE, Ross E, Webster PM, et al. Predictors of functioning of patients with chronic obstructive pulmonary disease. Heart Lung 1995;24:369-75.

9. Okubadejo AA, O'Shea L, Jones PW, et al. Home assessment of activities of daily living in patients with severe chronic obstructive pulmonary disease on long-term oxygen therapy. Eur Respir J 1997:10:1572-5.
10. Connors AF Jr, Dawson NV, Thomas C, et al. Outcomes following acute exacerbation of severe chronic obstructive lung disease. The SUPPORT investigators (Study to Understand Prognoses and Preferences for Outcomes and Risks of Treatments). Am J Respir Crit Care Med 1996;154:959-67.

11. Verbrugge LM, Jette AM. The disablement process. Soc Sci Med 1994;38:1-14

12. Eisner MD, Blanc PD, Yelin EH, et al. COPD as a systemic disease: impact on physical functional limitations. Am J Med 2008;121:789-96.

13. Eisner MD, Iribarren $\mathrm{C}$, Yelin EH, et al. Pulmonary function and the risk of functiona limitation in chronic obstructive pulmonary disease. Am J Epidemiol 2008;167:1090-101.

14. Blanc PD, Iribarren $\mathrm{C}$, Trupin $\mathrm{L}$, et al. Occupational exposures and the risk of COPD dusty trades revisited. Thorax 2009;64:6-12.

15. Omachi TA, Katz PP, Yelin EH, et al. Depression and health-related quality of life in chronic obstructive pulmonary disease. Am J Med 2009;122:778.e9-15.

16. Sidney S, Sorel M, Quesenberry CP Jr, et al. COPD and incident cardiovascular disease hospitalizations and mortality: Kaiser Permanente Medical Care Program. Chest 2005:128:2068-75

17. Centers for Disease Control and Prevention (CDC). Cigarette smoking among adults—United States, 1997. MMWR Morb Mortal Wkly Rep 1999:48:993-6.

18. American Thoracic Society. Standardization of spirometry - 1987 update. Statement of the American Thoracic Society. Am Rev Respir Dis 1987:136:1285-98.

19. Anon. Standardization of Spirometry, 1994 Update. American Thoracic Society. Am J Respir Crit Care Med 1995;152:1107-36.

20. Walters JA, Wood-Baker R, Walls J, et al. Stability of the EasyOne ultrasonic spirometer for use in general practice. Respirology 2006;11:306-10.

21. Perez-Padilla R, Vazquez-Garcia JC, Marquez MN, et al. The long-term stability of portable spirometers used in a multinational study of the prevalence of chronic obstructive pulmonary disease. Respir Care 2006;51:1167-71.

22. Buist AS, McBurnie MA, Vollmer WM, et al. International variation in the prevalence of COPD (the BOLD Study): a population-based prevalence study. Lancet 2007;370:741-50.

23. Sternfeld B, Ngo L, Satariano WA, et al. Associations of body composition with physical performance and self-reported functional limitation in elderly men and women. Am J Epidemiol 2002;156:110-21.

24. Eisner MD, Blanc PD, Sidney S, et al. Body composition and functional limitation in COPD. Respir Res 2007:8:7.

25. Tager IB, Haight T, Sternfeld B, et al. Effects of physical activity and body composition on functional limitation in the elderly: application of the marginal structural model. Epidemiology 2004;15:479-93.

26. Kendall FP, McReary EK, Provance PG. Muscles. Testing and Function. 4th edn Baltimore: Williams \& Wilkins, 1993

27. Hamilton AL, Killian KJ, Summers E, et al. Muscle strength, symptom intensity, and exercise capacity in patients with cardiorespiratory disorders. Am J Respir Crit Care Med 1995:152:2021-31.

28. Bernard S, LeBlanc $P$, Whittom F, et al. Peripheral muscle weakness in patients with chronic obstructive pulmonary disease. Am J Respir Crit Care Med 1998;158:629-34.

29. Gosker HR, Lencer NH, Franssen FM, et al. Striking similarities in systemic factors contributing to decreased exercise capacity in patients with severe chronic heart failure or COPD. Chest 2003;123:1416-24.

30. Gosselink R, Troosters T, Decramer M. Peripheral muscle weakness contributes to exercise limitation in COPD. Am J Respir Crit Care Med 1996;153:976-80.

31. Guralnik JM, Ferrucci L, Simonsick EM, et al. Lower-extremity function in persons over the age of 70 years as a predictor of subsequent disability. $N$ Engl $\mathrm{J}$ Med 1995:332:556-61.

32. Guralnik JM, Ferrucci L, Pieper CF, et al. Lower extremity function and subsequent disability: consistency across studies, predictive models, and value of gait speed alone compared with the short physical performance battery. J Gerontol A Biol Sci Med Sci 2000;55:M221-31

33. Guralnik JM, Simonsick EM, Ferrucci L, et al. A short physical performance battery assessing lower extremity function: association with self-reported disability and prediction of mortality and nursing home admission. J Gerontol 1994:49:M85-94.

34. Duncan PW, Weiner DK, Chandler J, et al. Functional reach: a new clinical measure of balance. J Gerontol 1990;45:M192-7.

35. Duncan PW, Studenski S, Chandler J, et al. Functional reach: predictive validity in a sample of elderly male veterans. J Gerontol 1992:47:M93-8.

36. Weiner DK, Duncan PW, Chandler J, et al. Functional reach: a marker of physica frailty. J Am Geriatr Soc 1992:40:203-7.

37. Weiner DK, Bongiorni DR, Studenski SA, et al. Does functional reach improve with rehabilitation? Arch Phys Med Rehabil 1993;74:796-800.

38. Guyatt GH, Sullivan MJ, Thompson PJ, et al. The 6-minute walk: a new measure of exercise capacity in patients with chronic heart failure. Can Med Assoc $\mathrm{J}$ 1985;132:919-23.

39. Sciurba F, Criner GJ, Lee SM, et al. Six-minute walk distance in chronic obstructive pulmonary disease: reproducibility and effect of walking course layout and length. Am J Respir Crit Care Med 2003;167:1522-7.

40. ATS Committee on Proficiency Standards for Clinical Pulmonary Function Laboratories. ATS statement: guidelines for the six-minute walk test. Am J Respir Crit Care Med 2002;166:111-17.

41. Fletcher C, Elmes PC, Fairbairn AS, et al. The significance of respiratory symptoms and the diagnosis of chronic bronchitis in a working population. Br Med J 1959:257-66. 
42. Bestall JC, Paul EA, Garrod R, et al. Usefulness of the Medical Research Council (MRC) dyspnoea scale as a measure of disability in patients with chronic obstructive pulmonary disease. Thorax 1999;54:581-6.

43. McGavin CR, Artvinli M, Naoe H, et al. Dyspnoea, disability, and distance walked: comparison of estimates of exercise performance in respiratory disease. $\mathrm{Br} \mathrm{Med} \mathrm{J}$ 1978;2:241-3.

44. Hajiro T, Nishimura K, Tsukino M, et al. Analysis of clinical methods used to evaluate dyspnea in patients with chronic obstructive pulmonary disease. Am J Respir Crit Care Med 1998:158:1185-9.

45. McDowell I, Newell C. Measuring Health: A Guide to Rating Scales and Questionnaires. New York: Oxford University Press, 1996.

46. Folstein MF, Folstein SE, McHugh PR. "Mini-mental state". A practical method for grading the cognitive state of patients for the clinician. J Psychiatr Res 1975;12:189-98.

47. Molloy DW, Alemayehu E, Roberts R. Reliability of a Standardized Mini-Menta State Examination compared with the traditional Mini-Mental State Examination. Am J Psychiatry 1991:148:102-5.

48. Fillenbaum GG, Heyman A, Wilkinson WE, et al. Comparison of two screening tests in Alzheimer's disease. The correlation and reliability of the Mini-Mental State Examination and the modified Blessed test. Arch Neurol 1987:44:924-7.

49. Faustman W0, Moses JA Jr, Csernansky JG. Limitations of the Mini-Mental State Examination in predicting neuropsychological functioning in a psychiatric sample. Acta Psychiatr Scand 1990;81:126-31.

50. Mitrushina M, Satz P. Reliability and validity of the Mini-Mental State Exam in neurologically intact elderly. J Clin Psychol 1991;47:537-43.

51. Rait G, Fletcher A, Smeeth L, et al. Prevalence of cognitive impairment: results from the MRC trial of assessment and management of older people in the community. Age Ageing 2005;34:242-8.

52. Katz PP, Yelin EH. The development of depressive symptoms among women with rheumatoid arthritis. The role of function. Arthritis Rheum 1995;38:49-56.

53. Katz PP, Yelin EH, Eisner MD, et al. Performance of valued life activities reflected asthma-specific quality of life more than general physical function. J Clin Epidemiol 2004; 57:259-67.

54. Katz P, Morris A, Gregorich S, et al. Valued life activity disability played a significant role in self-rated health among adults with chronic health conditions. J Clin Epidemiol 2009:62:158-66.
55. Katz PP, Gregorich S, Eisner M, et al. Disability in Valued Life Activities Among Individuals With COPD and Other Respiratory Conditions. J Cardiopulm Rehabil Prev 2010;30:126-36

56. Wyrwich KW, Tierney WM, Wolinsky FD. Further evidence supporting an SEMbased criterion for identifying meaningful intra-individual changes in health-related quality of life. J Clin Epidemiol 1999:52:861-73

57. Wyrwich KW, Nienaber NA, Tierney WM, et al. Linking clinical relevance and statistical significance in evaluating intra-individual changes in health-related quality of life. Med Care 1999:37:469-78.

58. Trupin L, Earnest G, San Pedro M, et al. The occupational burden of chronic obstructive pulmonary disease. Eur Respir J 2003;22:462-9.

59. Blanc PD, Yen $\mathrm{HH}$, Chen $\mathrm{H}$, et al. Area-level socio-economic status and health status among adults with asthma and rhinitis. Eur Respir J 2006;27:85-94.

60. DeLong ER, DeLong DM, Clarke-Pearson DL. Comparing the areas under two or more correlated receiver operating characteristic curves: a nonparametric approach. Biometrics 1988;44:837-45.

61. Pitta F, Troosters T, Spruit MA, et al. Characteristics of Physical Activities in Daily Life in Chronic Obstructive Pulmonary Disease. Am J Respir Crit Care Med 2005;171 972-7.

62. Pitta F, Takaki MY, Oliveira NH, et al. Relationship between pulmonary function and physical activity in daily life in patients with COPD. Respir Med 2008;102:1203-7.

63. Watz H, Waschki B, Meyer T, et al. Physical activity in patients with COPD. Eur Respir J 2009;33:262-72.

64. Garcia-Aymerich J, Serra I, Gomez FP, et al. Physical activity and clinical and functional status in COPD. Chest 2009:136:62-70.

65. Gosselink R, Decramer M. Peripheral skeletal muscles and exercise performance in patients with chronic obstructive pulmonary disease. Monaldi Arch Chest Dis 1998;53:419-23.

66. Jette DU, Manago D, Medved E, et al. The disablement process in patients with pulmonary disease. Phys Ther 1997;77:385-94.

67. Krieger N. Overcoming the absence of socioeconomic data in medical records: validation and application of a census-based methodology. Am J Public Health 1992;82:703-10.

68. McFarland BH, Freeborn DK, Mullooly JP, et al. Utilization patterns and mortality of HMO enrollees. Med Care 1986:24:200-8. 